\title{
Güray Müze'den Yeni Asurca Bir Etiket
}

\author{
Ömer Kahya*
}

\begin{abstract}
$\ddot{O}_{z}$
Bu çalışmanın amacı Güray Müze'de bulunan üçgen biçimli Yeni Asurca hububat borcu etiketini (G.M. 302) tanıtmaktır. Tabletin her iki yüzünde bir silindir mühür baskısı ve geniş kısmının köşelerinde ip deliği mevcuttur. 4+2+1 satırdan oluşmaktadır ve sağlam durumdadır. Etiketin yılı ve menşei/eyaleti bilinmemektedir.
\end{abstract}

Anahtar Kelimeler: Güray Müze, Yeni Asurca, Hububat Borcu, Etiket.

\section{A Neo-Assyrian Docket from the Güray Museum}

\begin{abstract}
The aim of this paper is to introduce a Neo-Assyrian triangular shaped barley loan docket from the Güray Museum in Nevşehir. There is a cylinder seal impression on its both sides and string holes on the corners of its large part. The docket which bears $4+2+1$ lines, is substantially complete. Its date and province is unknown.
\end{abstract}

Keywords: Güray Museum, Neo-Assyrian, Barley Loan, Docket.

Nevşehir'in Avanos ilçesinde yer alan ve sahibi Güray Tüysüz'ün adını taşıyan Güray Müze, kayalar oyularak yerin yaklaşık 20 m. altına inşa edilmiştir. Bu yönüyle dünyanın ilk ve (şu an için) tek yer altı müzesi olma özelliğini kazanan Güray Müze'de antik ve modern eserler sergilenmektedir. Geç Kalkolitik'ten Osmanlı Dönemi'ne kadar farklı devirlerden eserlerin bulunduğu müzede daha önce yayınlanmış iki Eski Asurca tabletin yanı sıra burada tanıtacağımız G.M. 302 envanter numarasıyla kayıtlı bir Yeni Asurca belge de yer almaktadır. ${ }^{1}$ Yeni Asur

* Dr., Ankara Üniversitesi, Dil ve Tarih-Coğrafya Fakültesi, Eskiçağ Dilleri ve Kültürleri Bölümü, Ankara/TÜRKIYE, kahyao@ankara.edu.tr ORCID: 0000-0003-2760-5133

Makale Gönderim Tarihi: 10.08.2018 - Makale Kabul Tarihi: 12.03.2019

$1 \mathrm{Bu}$ Yeni Asurca etiketi yayınlamam hususundaki müsaadelerinden dolayı Güray Tüysüz'e ve 
Dönemi'nde hububat borçlarının kaydedildiği bu tür belgeler, çoğunlukla üçgen/ muska biçimli olmakta ve etiket (docket/label) olarak isimlendirilmektedir. Üçgen biçimli bu etiketlere genellikle hububat borçları kaydedilse de şarap ve gümüş gibi başka malların borçlarını içeren örnekler bilinmektedir. Üzerlerinde mühür baskılarının da bulunduğu bu etiketlerin iki, bazen de üç kenarında iplik deliği görünmektedir. G.M. 302'nin ise iki kenarında delik bulunmaktadır.

Postgate, üçgen biçimli etiketlerin Aramca yazılı bir parşömen tomarına bağlanmış iplik üzerine şekillendirildiğini ve parşömendeki Aramca kaydın çivi yazılı versiyonu olabileceğini iddia etmektedir. Ayrıca yazar, içindeki tableti koruyan mühür baskılı zarflar gibi etiketlerin de tutturuldukları belgelerin ipliğinin çözülmesini engelleyerek onları koruduğunu düşünmektedir. ${ }^{2}$ Lipiński de bağlanmış bir ipliğin üzerine biçimlendirilen etiketlerin deri ya da papirüsten bir tomara iliştirildiğini söylemektedir. ${ }^{3}$ Fales ise Aramca tabletleri yayınladığı çalışmasında, bazıları Yeni Asurca-Aramca iki dilli, bazıları ise sadece Aramca yazılmış etiketlerin kendi başlarına belge niteliğinde olduklarını ve bir başka belgeye iliştirilmesi gerekmediğini belirtmektedir. Ayrıca ele aldığı metinlerden birinde yer alan Aramca ifadelerden hareketle, bu etiketlerin söz konusu hububatları içeren kaplara bağlanıyor olabileceğini söylemiştir4. Fales'ten çok daha önce Parker, kalp biçimli olarak isimlendirdiği bu etiketlerin muhtemelen bir çuvala bağlandığını ifade etmiştir. ${ }^{5}$ Aramca ve Yeni Asurca-Aramca iki dilli yazılmış etiketlerin varlığı göz önüne alındığında, Postgate ve Lipiński tarafindan dile getirilen üçgen etiketlerin bir iplikle Aramca içerikli belgelere bağlandığı ihtimali bizce de zayıflamaktadır. Etiketlerde kaydedilmiş olan hububatın bulunduğu kaplara asıldıkları görüşü daha makul olabilir.

yardımları için Murat Ertuğrul Gülyaz'a teşekkür ederim.

2 Yazar ayrıca Persepolis’ten ele geçen Elamca etiketlerin de üçgen biçimli ve bir düğüm üzerine biçimlendirilmesi bakımından Yeni Asurca olanlarla benzerlik gösterdiğini belirtmiştir bkz. J. Nicolas Postgate, "Neo-Assyrian Private Archive Texts from the Seventh Century B.C. Primarily from Nimrud", eds. Ira Spar and Eva Von Dassow (with contributions by J.N. Postgate and L.B. Bregstein), Cuneiform Texts in the Metropolitan Museum of Art, Volume III. Private Archive Texts From The First Millennium B.C., New York 2000, s. 3 vd.; J. Nicolas Postgate, Fifty Neo-Assyrian Legal Documents, Warminster 1976, ss. 5-6.

3 Edvard Lipiński, Studies in Aramaic Inscriptions and Onomastics, Volume III: Ma lānā (OLA 200), Leuven 2010, s. 29.

4 F. Mario Fales, Aramaic Epigraphs on Clay Tablets of the Neo-Assyrian Period, Rome: Universita degli Studi "La Sapienza", 1986, s. 24. Söz konusu metnin (no. 15) ilgi kısmının yorumu için s. 169'a bakınız.

5 Barbara Parker, "Nimrud Tablets, 1956: Economic and Legal Texts from the Nabu Temple", Iraq, C. 19/S. 2, (1957), s. 125. 
Yeni Asur dönemine tarihlenen ve hububat borçlarının kaydedildiği etiketlerde yer alan bilgiler şöyledir:

1. Hububatın miktarı, türü ve ölçüldüğü kabın hacmi.

2. Borcu veren kişi ( $s a$ Şahıs Adı).

3. Borcu alan kişi/kişiler (ina pāni Şahıs Adı/Adları).

4. Borcun geri verileceği ay/tarih (ina ITI Ay Adı tadānu).

5. "Borç olarak aldı/aldılar" ifadesi (ina pühi našû) ve uygulanacak faiz miktarı (eğer metinde, 4. maddedeki ifade (ina ITI Ay Adı tadānu) varsa bu maddedeki ifadeler görünmez).

6. Borç ödenmediği takdirde (šumma la tadānu) uygulanacak ceza (bu madde 4. maddedeki ifadeler varsa metinde yer alır).

7. Hasatçı ifadesi ((LÚ.)ŠE.KIN.KUD).

8. Borcun alındığı tarih (ay, gün, yıl (līmu) olarak belirtilir).

9. Teminat (nadiren görünür).

10. Kefil (nadiren görünür).

11. Şahit/Şahitler (metin içindeki yeri değişebilir).

$\mathrm{Bu}$ maddelerdeki bilgilerin hepsi her etikette bulunmaz ve siralamaları da metinden metine farklılık gösterebilir. ${ }^{6}$ Ele aldığımız etikette hububat miktarı, borcu veren, borcu alan, hasatçı ifadesi, borcun ödeneceği tarih, bir şahit ve borcun alındığı tarih bulunmaktadır.

G.M. 302, Atiya isimli bir kadının Kakkussu'dan bizim de neredeyse aynı telaffuzla kullanmaya devam ettiğimiz ve yllın ilk ayı kabul ettikleri Nisannu'da aldığı belirli miktardaki arpa borcunu içermektedir. Muhtemelen borç aynı yıl içinde ödeneceğinden yıl (līmu) belirtilmemiştir. Ödeme tarihine baktığımızda yaklaşık 4 aylık bir süre verildiği anlaşılmaktadır. Siyah renkli bu etiketin her iki yüzünde mühür baskısı bulunur. Aslında sadece bir silindir mühür önyüzden başlayıp arka yüze doğru basılmıştır. Mühür baskısı, bir kahraman tarafindan tutulan iki ceylana(?) bir aslanın saldırışını resmetmektedir.

6 Simonetta Ponchia, "Neo-Assyrian Corn-Loans: Preliminary Notes", State Archives of Assyria Bulletin, S. 4 (1990), s. 40. Yazar burada çeşitli arşivlerdeki hububat borçlarıyla ilgili etiketleri ele almış ve içerdikleri bilgileri numaralandırarak sınıflandırmıştır. 
G.M. 302

Öy. 1) 1 ANŠE 5 BÁN ŠE.PAD EN ŠÚ GAR

Silindir Mühür Baskısı

2) $s^{\check{a} a} \mathrm{md} \mathrm{PA}-k a-s ̌ r r$

3) ina IGI ${ }^{\mathrm{A}} A-t i-i a$

4) 1-en ŠE.KIN.KUD

Ay. 5) ina ITI.NE ta-SUM-an

6) IGI ${ }^{\mathrm{m}} K a-k u-s u$

Silindir Mühür Baskısı

7) ITI.BARAG UD.21.KAM

1-4) Nabû-kāšir'e ait ... 1 eşek yükü 5 sāt arpa, Atiya'nın kullanımındadır. 1 hasatçı (temin edecek). ${ }^{5-7)} \mathrm{Ab}$ ayında (5. ay) (geri) verecek. Şahit Kakkussu. Nisannu ayının (1. ay) 21. günü.

Genellikle ŠE.PAD.MEŠ yazılışı ile geçen ve Yeni Asurca karşılığının kurummatu olduğu kabul edilen "arpa; arpa payı/tayını" anlamındaki kelime, metnimizdeki gibi nadiren ŠE.PAD şeklinde geçmektedir. Bu ifadenin ardından yukarıda da belirttiğimiz gibi arpanın ölçüldüğü kabın hacmi (ina GIŠ.BÁN ša X qa) hakkında bilgi verilir ancak takip eden işaretleri (EN ŠÚ GAR) herhangi bir ölçü birimiyle bağdaştıramadik. Hububat borcu metinlerinde ya da diğer borç senetlerinde bu kısmı anlamamıza yardım edecek benzer bir örnek ile karşlaşmamaktayız. Buradaki işaretleri EN-šú GAR “(1 eşek yükü 5 sāt arpanın) sahibi koydu” ya da "sahibi tarafindan konulan (1 eşek yükü 5 săt arpa)" şeklinde değerlendirdiğimizde ise maskülen enklitik şahıs elemanı -šu, feminen bir isim olan kurummatu "arpa" ile uyumsuzluk arz eder. Alternatif olarak ina X-ša "onun(borçlu kadının) ....-kabı ile ölçülen” şeklinde düşünülebilir ancak metinlerde bu durumu destekleyen bir geçiş bulunmamaktadır. İşaretleri, farklı okunuşları ve karşılıklarıyla değerlendirmeye çalı̧şak da tatmin edici bir çeviri elde edilememektedir. Dolayısıyla bu kısmın kâtip tarafindan yanlış yazılmış olma ihtimali de düşünülebilir. 
G.M. 302'de geçen Nabû-kāširir (borç veren) ve Kakkussu ${ }^{8}$ (şahit) isimleri ile başka belgelerde de karşılaşmaktayız. Aynı kimseler olup olmadıklarını anlamak için baba adı, nereli olduğu ve ismin geçtiği belgenin düzenlendiği tarih gibi bilgiler gerekmektedir. G.M. 302'de ise bu bilgilerin hiçbiri bulunmadığından şahıslar hakkında ilave bilgi veremiyoruz. Fakat Kral Sanherib'in Asur'da yeni inşa ettirdiği Akītu tapınağına personel olarak verdiği ve Raṣappa'dan gelen insanların isimlerinin yer aldığı metinde ${ }^{9}$ hem Nabû-kāšir hem de Kakkussu'nun geçtiğini görüyoruz. Nabû-kāšir tapınak personeli, kâtip unvanıyla kayıtlı olan Kakkussu ise şahitler arasında yer almaktadır. Ancak Nabû-kāšir ve Kakkussu şahıs adlarının hem G.M. 302'de hem de SAA 12, 86'da birlikte geçmesi, aynı kişiler olduklarını söylemek için yeterli değildir. Aynı kimseler olduklarını varsayarsak, Nabû-kāšir Asur'daki Akītu tapınağında görevli olarak belki de tapınağın arpasını borç vermekte ve kâtip Kakkussu da hem belgeyi düzenlemekte hem de şahitlik yapmaktadır diyebiliriz. Bu durumda G.M. 302'nin yazıldığı zaman, kral Sanherib’in dönemi (M.Ö. 704-681) ve menşei de muhtemelen Asur şehri olurdu.

Hububat borcuyla ilgili belgelerde borcu veren ve alan kimseler çoğu zaman erkektir. Bildiğimiz kadarıyla borçlu kimseler içeresinde Atiya dışında ismiyle birlikte kaydedilmiş başka bir kadın yoktur. ${ }^{10}$ Bahianu'nun bir rahibeye (NIN.DINGIR.RA/ entu) verdiği arpa borcunu içeren etiket, ${ }^{11}$ bir kadının borç almasına dair bir diğer ünik belgedir. Borçlunun yazılı olduğu kısım ( $\left\ulcorner\right.$ MÍ* ${ }^{*}$.NIN*.DINGIR.RA) kısmen hasarlıdır ve eğer doğru okunduysa bir kadın, adı yerine unvanıyla kaydedilmiştir.

7 Heather Baker, The Prosopography of the Neo-Assyrian Empire, Volume 2, Part 2: L-N , Helsinki 2001, s. 839.

8 Heather Baker, The Prosopography of the Neo-Assyrian Empire, Volume 2, Part 1: H-K, Helsinki 2000, s. 597.

9 SAA 12, 86: st. 25’te Nabû-kāšir, st. 31'de Kakkussu geçmektedir bkz. Theodore Kwasman Simo Parpola, Legal Transactions of the Royal Court of Nineveh, Part I: Tiglath-Pileser III through Esarhaddon, State Archives of Assyria, Volume VI, Helsinki 1991, s. 106.

10 Hububat borcuyla ilgili bir kadın adı ile karşılaşmasak da SAA 6, 81 numaralı metinde šakintu (bir kadın yönetici) unvanlı Addati’nin 2 mina gümüşü Bibiya’ya borç verdiğini görüyoruz bkz. Theodore Kwasman - Simo Parpola, a.g.e., s. 72. Ayrıca belgelerde isimi belirtilmeyen šakintuların borç verdiğine dair başka örnekler de bulunmaktadır: SAA 6, 84; 247 bkz. Kwasman - Parpola, a.g.e., s. 73, 198; SAA 14, 471 bkz. Raija Mattila, Legal Transactions of the Royal Court of Nineveh, Part II: Assurbanipal Through Sin-šarru-iškun, State Archives of Assyria, Volume XIV, Helsinki 2002, ss. 302-303. šakintu ile ilgili daha ayrıntılı bilgi için bkz. Saana Svärd, Power and Women in the Neo-Assyrian Palace, Helsinki University Print, Helsinki 2012, ss. 150-156.

11 Mattila, a.g.e., s. 71. 
Metnimizin 4. satırında geçen "hasatçı" ifadesi her etikette karşımıza çımmamaktadır. Aramca etiketlerde de görünebilen bu ifadeyle borçlunun hasat zamanında borç veren kimsenin tarlasında çalışması için temin etmesi gereken işçi/hasatçı sayısının belirtildiği kabul edilmektedir. ${ }^{12}$ Arpa borcu ile ilgili olan ND 5465 numaralı etiketteki "O bir hasatçı verecek." ve ND 5469'da geçen "Hububatı harman yerinde, hasatçıları hasatta verecekler." cümleleri, bu düşünceyi doğrular. ${ }^{13}$ Borç miktarı olan eşek yükü sayısı ile temin edilecek hasatçı sayılarına baktı̆̆ımızda aralarındaki orantı dikkat çekmektedir. Bu orantıya göre 1 eşek yükü hububatın karşılığı 1 hasatçıdır. Ancak 50 hasatçıya 10 eşek yükü veya 1 hasatçıya 6 eşek yükü hububatın verildiği örnekler de vardır. ${ }^{14}$ Hatta metnimizde de 1 eşek yükü 5 săt $t^{15}$ için 1 hasatçı istenmektedir. Radner, hasatçı için ND 2083 nolu etikette kesirli sayı geçtiğini belirtmektedir. Yazar aynı durumun Eski Babil Dönemi metinlerinde de görüldüğünü ve Stol'un bu kesirli sayıları hasatçıların çalısması için hesaplanan gün şeklinde değerlendirdiğini söylemektedir. ${ }^{16}$

Burada ele aldığımız G.M. 302 müze envanter numaralı metin, tarihleme için gerekli olan tìmu ismini sunmaz. Fakat büyük olasilıkla çoğu Yeni Asurca ve Aramca etiket gibi M.Ö. 7. yüzyllda meydana getirilmiştir. Bu belge, borçlu olarak bir kadın adının ilk kez kaydedilmesi bakımından üniktir. Hatta Atiya ismiyle de daha önce karşlaşmamaktayız. Hangi arşive ait olduğunu tespit edemediğimiz etiketin dikkat çeken bir diğer yönü, birinci satırın sonunda geçen ve bu tür belgelerde daha önce hiç görünmeyen bir ifadeyi barındırıyor olmasıdır. Asurca belgelerden sūtu ile qû arasındaki oranın her zaman 1/10 olmadığı anlaşılmaktadır bkz. tions", State Archives of Assyria Bulletin, sy. 16 (2007), s. 172.

16 Radner, a.g.m., s. 15. 


\section{KAYNAKLAR}

Baker, Heather, The Prosopography of the Neo-Assyrian Empire, Volume 2, Part 1: H-K, Helsinki 2000.

Baker, Heather, The Prosopography of the Neo-Assyrian Empire, Volume 2, Part 2: L-N , Helsinki 2001.

Fales, F. Mario, Aramaic Epigraphs on Clay Tablets of the Neo-Assyrian Period, Universita degli Studi "La Sapienza", Rome 1986.

Gaspa, Salvatore, "Vessels in Neo-Assyrian Documents Capacity Measures and Listing Conventions", State Archives of Assyria Bulletin, S. 16 (2007), ss. 145-184.

Kataja, Laura - Whiting, Robert, Grants, Decrees and Gifts of the Neo-Assyrian Period, State Archives of Assyria, Volume 12, Helsinki 1995.

Kwasman, Theodore - Parpola, Simo, Legal Transactions of the Royal Court of Nineveh, Part I: Tiglath-Pileser III through Esarhaddon, State Archives of Assyria, Volume 6, Helsinki 1991.

Lipiński, Edvard, Studies in Aramaic Inscriptions and Onomastics, Volume III: Ma lānā (OLA 200), Leuven 2010.

Mattila, Raija, Legal Transactions of the Royal Court of Nineveh, Part II: Assurbanipal Through Sin-̌̌arru-iškun, State Archives of Assyria, Volume 14, Helsinki 2002.

Parker, Barbara, "Nimrud Tablets, 1956: Economic and Legal Texts from the Nabu Temple", Iraq, G. 19/S. 2 (1957), ss. 125-138.

Ponchia, Simonetta, "Neo-Assyrian Corn-Loans: Preliminary Notes", State Archives of Assyria Bulletin, S. 4 (1990), ss. 39-60.

Postgate, J. Nicolas, "Neo-Assyrian Private Archive Texts from the Seventh Century B.C. Primarily from Nimrud", eds. Ira Spar and Eva Von Dassow (with contributions by J.N. Postgate and L.B. Bregstein), Cuneiform Texts in the Metropolitan Museum of Art, Volume III. Private Archive Texts From The First Millennium B.C., New York 2000, ss. 3-13.

Postgate, J. Nicolas, Fifty Neo-Assyrian Legal Documents, Warminster 1976. 
Radner, Karen, "Erntearbeiter und Wein. Neuassyrische Urkunden und Briefe im Louvre", State Archives of Assyria Bulletin, S. 11 (1997), ss. 3-29.

Svärd, Saana, Power and Women in the Neo-Assyrian Palace, Helsinki University Print, Helsinki 2012. 
Ömer Kahya

\section{EK}

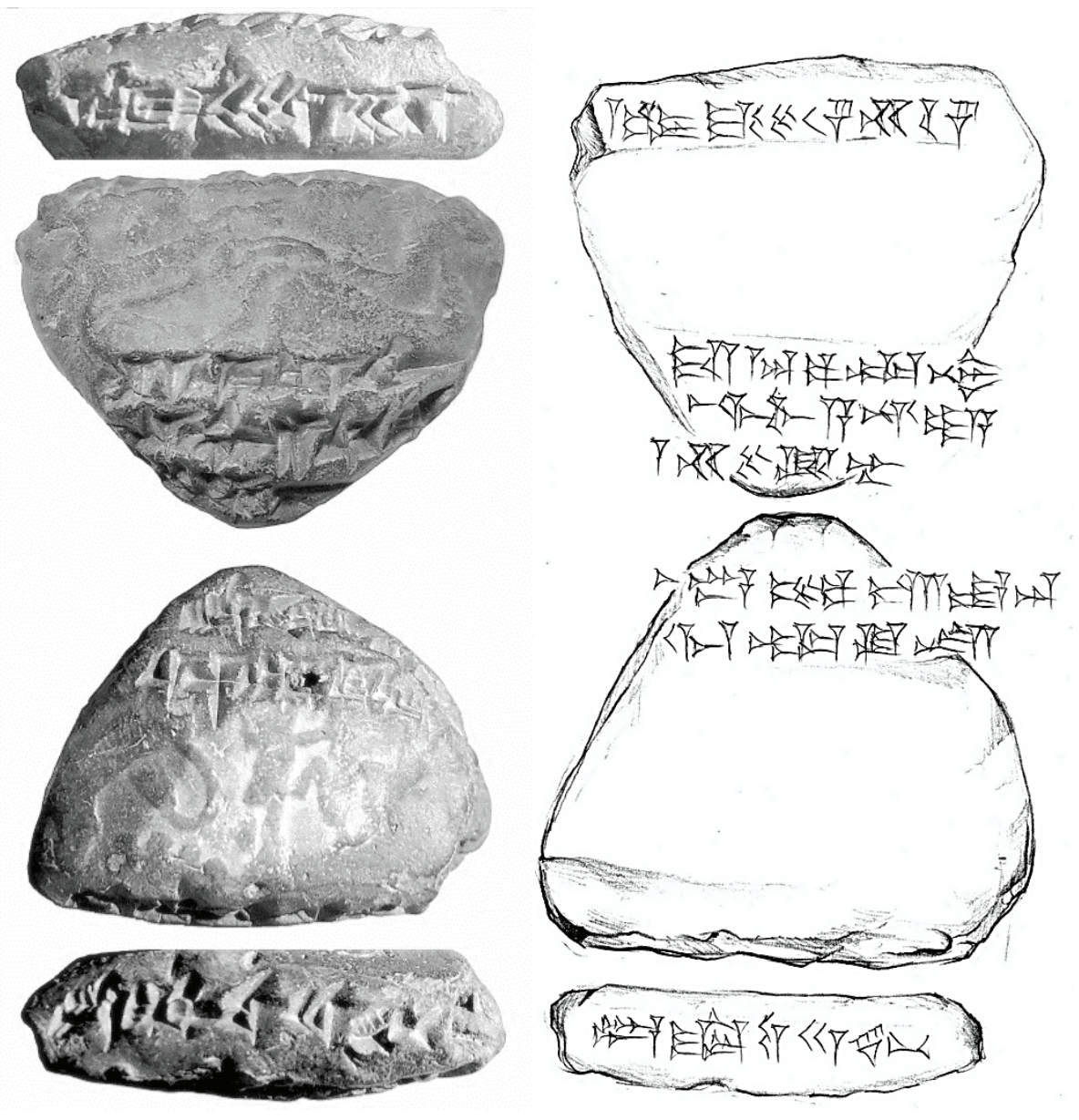

G.M. $302^{17}$

17 Metnin kopyası Dr. Faruk Akyüz tarafından yapılmıştır. 
